\title{
Breastfeeding Status and Effective Factors in 21 - 27 Months Iranian Infants
}

\author{
Fatemeh Nayeri1, Mamak Shariat1', Hosein Dalili2*, Farima Raji², Akram Karimi2 \\ ${ }^{1}$ Maternal, Fetal and Neonatal Research Center, Tehran University of Medical Sciences, Tehran, Iran \\ ${ }^{2}$ Breast Feeding Research Center, Tehran University of Medical Sciences, Tehran, Iran \\ Email: fsnayeri@sina.ac.ir, mshariat@tums.ac.ir, ${ }^{*}$ hoseindalili@yahoo.com, mfnhrc@yahoo.com, \\ mfnhrc@tums.ac.ir
}

Received 20 April 2015; accepted 1 June 2015; published 8 June 2015

Copyright (C) 2015 by authors and Scientific Research Publishing Inc.

This work is licensed under the Creative Commons Attribution International License (CC BY).

http://creativecommons.org/licenses/by/4.0/

(c) $\underset{\mathrm{EY}}{\mathrm{P}}$ Open Access

\section{Abstract}

The aim of this study was to assess the Breastfeeding status among children aged 21 - 27 moths. A cross sectional study was carried out in South Health Center (Tehran-Iran) in 2010. Four hundred 21 - 27 month breastfed infants entered the study. This study compared some variables in 2 groups; weaning before and after 22 months. The level of significance was considered $P<0.05$. Mean breastfeeding duration and median (either exclusive or combined) were $19.66 \pm 6.40$ and 22 months. Among all reasons were cited by mothers, some reasons like insufficient breast milk supply $(\mathbf{7 7 . 9 \% )}$ ), infant restless $(\mathbf{7 7 . 1 \%})$, and Mother's reluctance $(\mathbf{7 5 . 6 \% )}$ ) were the most common causes of exclusive breastfeeding cessation. A significant relation was seen between breastfeeding duration and gestational age or birth trauma $(P$ Value $=0.031, P$ Value $=0.04)$. Breastfeeding training and First mother-infant skin to skin contact had significant roles on breastfeeding duration ( $\mathrm{P}$ Value $<0.05$, $\mathrm{P}$ Value $\mathbf{0} \mathbf{0 . 0 0 1}$, respectively). It seems lots of public health efforts and policy are needed to improve breastfeeding rate in our country.

\section{Keywords}

Infant, Breastfeeding Rate, Iran

\section{Introduction}

There is no doubt that breastfeeding is ideal infant's nutrition. It is a source of protein, lipid, oligosaccharide, vitamins, elements, hormones, enzymes, growth and immune factors that can adjust over time based on infant's need [1]. Breastfeeding protects children against respiratory tract infections, atopic dermatitis, asthma, type II

\footnotetext{
"Corresponding author.
}

How to cite this paper: Nayeri, F., Shariat, M., Dalili, H., Raji, F. and Karimi, A. (2015) Breastfeeding Status and Effective Factors in 21 - 27 Months Iranian Infants. Open Journal of Pediatrics, 5, 156-163. 
diabetes, obesity, and sudden infant death syndrome [2]. Suboptimal breastfeeding is responsible for children death (under 5 years old) due to infections (45\%), diarrhea (30\%) and acute respiratory disease (18\%) [3]. Moreover, breastfeeding is beneficial to the mother's health by returning pelvic organs to prior pregnancy condition, delaying next pregnancy and protection against ovarian and breast cancer [4].

In the USA breast feeding rate is $70 \%$ at hospital discharge, but this rate declines to $50 \%$ in 6 months and $25 \%$ in 24 months [5]. Some elements like personal, cultural, social, environmental, and psychological characteristics, acceptance of female role, breastfeeding experience, infant health status and belief of insufficient milk supply affect on breastfeeding tendency [2]. Pre and post natal breastfeeding training are also considered influential [6]. In addition intra partum mothers' training such as rooming-in and skin to skin contact influence on breastfeeding success [7]. American Academy of Family Physicians (AAFP) suggest intra partum training, physicians' support and improving educational breastfeeding methods can promote breastfeeding initiation and duration [8].

Mothers face lots of advertisement about formula and complementary feeding but information about breast pump and milk storage are not enough that can affect on breast feeding trend [9]. Different statistics of breastfeeding rates were published from different Iranian provinces [10]-[12]. This study was to assess breastfeeding frequency in 21 - 27 month infants born in Baby Friendly Hospitals (Tehran-Iran) by characteristics of the child and mother. Evaluation of effective factors can suggest some interventions to promote breastfeeding success.

\section{Materials and Methods}

A descriptive-cross sectional study was carried out in South Health Center (Tehran-Iran) in 2010. Four hundred 21 - 27 month single (not twin or more) breastfed infants entered the study. Exclusion criteria were mothers' dissatisfaction, separation of mother and baby due to hospitalization, mother's illness or drug consumption with absolute contra indication in breastfeeding period. Exclusive breastfeeding and breastfeeding duration were clarified based on WHO definition [13]. A questionnaire compatible with other studies and confirmed by experts was applied. Veteran and trained midwives completed questionnaires in a pilot study then its validity and reliability were assessed (Cronbach's alpha $=75 \%$ ).

The aim of the study and its process were described for all participants, and then all demographic data (infants' birth weight, height, and mothers' age, educational level, occupation, past medical and Ob history, drug consumption except from routine prenatal and breastfeeding period medications) were gathered and recorded in the questionnaires.

In next step investigators asked mothers to answer questions about breastfeeding initiation time, exclusive breast feeding, duration of breastfeeding, initiation of formula and their reasons, time of weaning and it's causes, any medical complications like allergies, baby satisfaction, nipple sore, any breastfeeding training in pre, intra and postpartum periods, attendance and non-person training, skin to skin contact, and role of father's support in their breastfeeding.

Patients' data were considered secret and as no interventions were performed in our study, no patient's consent was asked. Ethics approval for the study was obtained from the institutional review board of Tehran University of medical sciences (ID: 12043).

Finally the software package SPSS version 16 was used to perform the statistical analysis. The t-test, Chi square and Pearson Correlation Coefficient were applied where applicable. The power of study was $80 \%$ and level of significance was considered $\mathrm{P}<0.05$.

\section{Results}

Among four hundred, 21 - 27 month infants' mothers with mean gestational age 38.16 weeks, 340 (85\%) mothers were under High School diploma and 388 (97\%) were unemployed and housekeeper. forty five percent mothers had 1 - 3 abortions. Thirty two mothers (8\%) had underlying disease of which $7 \%$ used psychological drugs, $1 \%$ cardiovascular, $26 \%$ antibiotic and $21 \%$ took other drugs. Three hundred and eleven mothers were trained by physicians, midwives, family, relatives, press, media and breastfeeding classes in hospitals.

Of 400 breastfed infants born in Baby Friendly Hospitals with mean birth weight $3228+438$ gram, 216 (54\%) were female.

Based on our results unfortunately $25 \%$ of mothers have not had any breastfeeding. Of 300 others, 52 mothers (17\%) had Exclusive 6 month's breastfeeding, 87\% breastfed their infants until 12 while 36\% had breastfeeding until 24 months. Participants' breastfeeding trend was shown in Figure 1. 


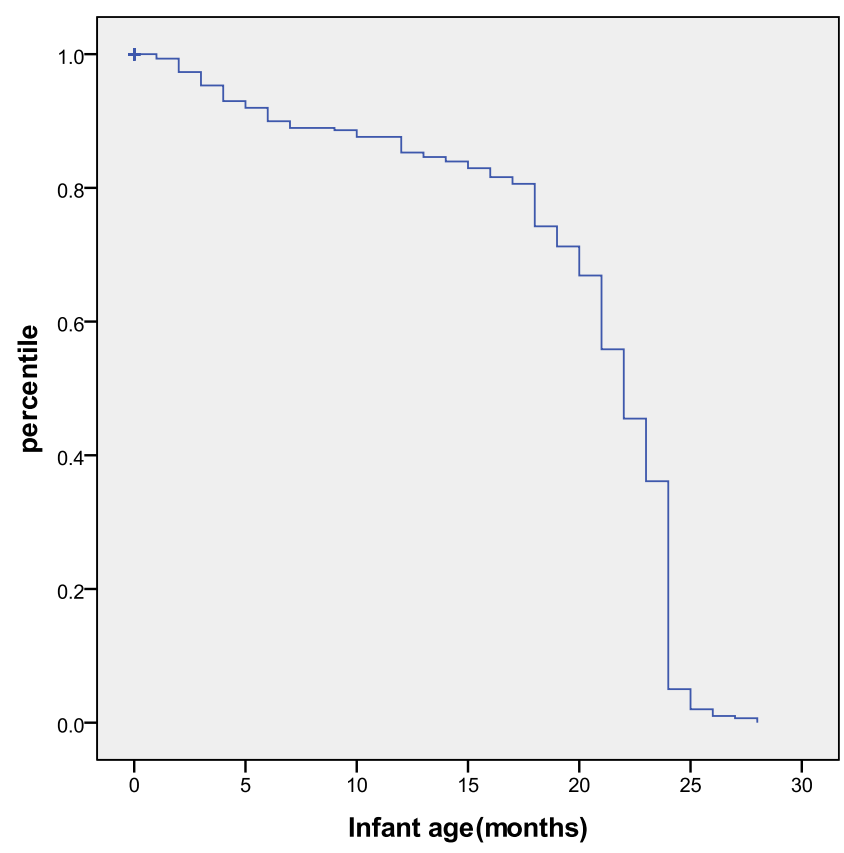

Figure 1. Trend of breastfeeding duration in 22 - 27 months infants' mothers.

Mean breastfeeding duration and median (either exclusive or combined) were $19.66 \pm 6.40$ and 22 months. Two hundred and forty eight mothers had added formula before 6 months. Table 1 shows mothers' reasons for formula initiation.

Among all reasons which cited by mothers, Some reasons like insufficient breast milk supply (77.9\%), mothers' occupation (73.3\%), physician and family's recommendation $(74.8 \%, 76 \%)$, infant crying and restless (77.1\%), Mother's reluctance (75.6\%) and infant refuse (74\%) were the most common causes of stopping exclusively breastfeeding until 6 months while vaccination (8.2\%), breast congestion (3.2\%), oral thrush (1.6\%), earache $(1.6 \%)$, teething $(1.7 \%)$, and use of cosmetics $(1.7 \%)$ were the least common causes. In addition no cases reported stop breast feeding due to fast flow milk, breast shaking or blistering and skin inflammation.

As breastfeeding median was 22 months, investigators compared some variables in 2 groups; Group A: weaning before 22 months and Group B: weaning after 22 months. Breastfeeding was stopped in 133 infants in group A and 165 infants in group B. Table 2 shows comparison of two groups' demographic data.

A significant relation was seen between breastfeeding duration and gestational age (P Value $=0.031)$. Stopping breast feeding was more frequent in mothers with lower gestational age (in Group A gestational age was $37.73 \pm$ 3.48 while in Group B was $38.49 \pm 2.52$ weeks). First mother-infant skin to skin contact was seen in 99(60\%) cases in group B and $63(47 \%)$ cases in group $\mathrm{A}$, which this difference was significant $(\mathrm{P}$ Value $=0.001)$. A significant correlation was seen between breastfeeding duration and birth trauma (P Value $=0.04)$. Pre, intra and postpartum breastfeeding training especially private and face to face training by physicians had a significant role on breastfeeding duration (Table 3). Besides that father's support was important factor on breastfeeding trend (P Value $<0.05)$.

In two groups, no significant correlations were observed between weaning or adding formula and some factors mentioned by mothers like mothers' occupation $(\mathrm{P}$ Value $=0.804)$, physicians' encouragement $(\mathrm{P}$ Value $=$ $0.299)$, insufficient breast milk supply ( $\mathrm{P}$ Value $=0.465)$, family advice $(\mathrm{P}$ Value $=0.423)$, baby crying $(\mathrm{P}$ Value $=0.465)$, infant refuse $(\mathrm{P}$ Value $=0.811)$, Mothers reluctance $(\mathrm{P}$ Value $=0.351)$.

No relation was seen with infant’s birth weight (Group A; $3219 \pm 467$, Group B $3235 \pm 415$, P Value = 0.753). More over this study could not find any relation between stop breastfeeding and mother's parity (Group A; $1.59 \pm$ 0.7, Group B; $1.79 \pm 1$, P Value $=0.059$ ). Maternal age and infant's sex also were not significant factors on mean breastfeeding duration and even breastfeeding initiation time. No relation was found with drug consumption, too $(\mathrm{P}$ Value $=0.140)$. 
Table 1. Effective factors on initiation of formula (both Breastfeeding and formula).

\begin{tabular}{cc}
\hline Variables & Both breastfeeding and formula total $=248$ [n\%] \\
Baby refuse & $188(76)$ \\
Insufficient breast milk supply & $198(80)$ \\
Mother's return to work & $186(75)$ \\
Encourage by physician & $191(77)$ \\
Baby cry and restless & $198(80)$ \\
Mothers reluctance & $191(77)$ \\
Encourage by family members & $188(76)$ \\
\hline
\end{tabular}

Table 2. Demographic factors in 2 groups; weaning before and after 22 months.

\begin{tabular}{|c|c|c|c|c|}
\hline Demographic characteristics & & $\begin{array}{c}\text { Weaning before } 22 \\
\text { months total = } 133[\mathrm{n} \%]\end{array}$ & $\begin{array}{c}\text { Weaning after } 22 \\
\text { months total = } 165[\mathrm{n} \%]\end{array}$ & $\mathrm{P}$ value \\
\hline Education & $\begin{array}{l}\text { Under diploma } \\
\text { Upper diploma }\end{array}$ & $\begin{array}{l}45(34) \\
88(66)\end{array}$ & $\begin{array}{c}56(33.9) \\
109(66.1)\end{array}$ & 0.987 \\
\hline Job & $\begin{array}{l}\text { Housekeeper } \\
\text { Employed }\end{array}$ & $\begin{array}{c}128(96) \\
5(4)\end{array}$ & $\begin{array}{c}162(98) \\
3(2)\end{array}$ & 0.758 \\
\hline Underlying disease & $\begin{array}{l}\text { Yes } \\
\text { No }\end{array}$ & $\begin{array}{c}17(13) \\
116(87)\end{array}$ & $\begin{array}{c}13(7.8) \\
152(92.2)\end{array}$ & 0.145 \\
\hline Drug consumption & $\begin{array}{l}\text { Yes } \\
\text { No }\end{array}$ & $\begin{array}{c}19(14) \\
114(86)\end{array}$ & $\begin{array}{c}15(9) \\
150(91)\end{array}$ & 0.140 \\
\hline Breastfeeding experience & $\begin{array}{l}\text { Yes } \\
\text { No }\end{array}$ & $\begin{array}{l}56(42) \\
77(58)\end{array}$ & $\begin{array}{l}78(47) \\
89(53)\end{array}$ & 0.583 \\
\hline
\end{tabular}

Table 3. Effects of training on breastfeeding duration.

\begin{tabular}{cccc}
\hline Variables & Group A Total = 133 & Group B Total = 165 & P value \\
\hline Breastfeeding training & $74(56.2)$ & $118(72)$ & 0.0001 \\
Training by physicians at office & $12(9.0)$ & $26(15.6)$ & 0.045 \\
Prenatal training & $4(3.0)$ & $12(7.2)$ & 0.050 \\
Intra partum training & $21(15.5)$ & $39(23.4)$ & 0.046 \\
Postpartum training & $55(42.1)$ & $85(52)$ & 0.047 \\
\hline
\end{tabular}

\section{Discussion}

The benefits of breast feeding for mother and her infant are well-documented, however, these effects depends on its duration and exclusivity [14]. Our analysis provided further explores the rates of breastfeeding in Teheran-Iran by characteristics of the infant and mother. The main strengths of this study were the large sample size and evaluating the status of breastfeeding in 21 - 27 months infants which had not been done previously in other studies from Iran.

The project found that $17 \%$ of our participants were exclusively breastfed by 6 months. Although this prevalence rate was lesser than Saudi Arabia and China, Compared to WHO report (1.7\% - 24.4\%) it was appropriate. In Saudi Arabia and China exclusive breastfeeding rate were reported 32\% - 38\% and 70\% which seems differences in cultures, believes, training and breastfeeding social supports are responsible for such discrepancies [15] [16]. Maybe in our country exclusive breastfeeding was being replaced by a combination of breast milk and formula.

This study found that the mean breastfeeding duration was $19.66 \pm 6.40$ which was near to another report from Iran by 20.6 months [12]. Fortunately about $90 \%$ of our participants had breastfeeding until 12 months. It 
shows breast feeding is preferred nutrition for Iranian infants in one and two-years of age. Our religion (Islam) and governmental strategies highly emphasized on breastfeeding, too. Africa and Asia have the highest rate of breast-feeding duration while the USA has the lowest [11].

This study like previous reports indicated that in spite of large number breast feeding initiation rate, this rate declined at 27 months postpartum. Our results consistent to another local study (2014) which showed $65.8 \%$ of Iranian mothers had breastfeeding in 4 first months but this rate decreased to 24 months [2]. Spears and Garbarino in their studies also revealed that the prevalence rate of the breastfeeding initiation rate was much more than breast feeding sustaining after 6 months or latter [17] [18].

Our finding indicated that some formula was added for $82.7 \%$ of infants in 24 months. Based on mothers' reports initiation of formula was due to family advice, breast refusal by infant, insufficient milk supply, return to work, physicians' recommendation, baby crying and mother's unwillingness. Tararnt et al. (2010) in their study also pointed to husband preference, milk insufficiency and mother's occupation as important factors for adding formula [19]. Another study indicated that initiation of formula may be due to mother's reluctance, baby restless, return to work and milk insufficiency. Although $50 \%$ of mothers mentioned inadequacy of their milk, no evidences such as infant weight loss were seen [20] [21]. Providing work places more friendly towards breastfeeding for employed mothers, finding the related factors to perception of insufficient milk, solving problems, use of medications to increase milk supply, and confirmation of milk insufficiency by physicians before initiation of formula can encourage mothers to continue their breastfeeding [22] [23].

A significant relation was seen between mother's gestational age and breastfeeding duration. Breastfeeding duration in mothers with a term infant is longer than a preterm. Nagulesapillai et al. explained that mothers with preterm infants need more attention for breastfeeding continuity [24]. Haschke et al. also reported that in developed and developing countries term in compare to preterm infants benefit more from mother's milk [25]. In addition because preterm infants receive little milk, breastfeeding success need more attempt and support. Mothers preterm infants after hospital discharge did not have enough experience and knowledge due to bottle milk or formula feeding which started in the hospital [26].

This study of mothers in Tehran has identified the important role of face to face training by physicians at private office. Physicians' supportive and educational program, guidance on breast-feeding techniques and ways to resolve problems bedside increasing the rate of exclusive breastfeeding, decrease cessation of breastfeeding at birth time, first month and 1 to 5 months of life [27]. Honda et al. showed in their investigation that physicians have a key role in mothers' inspiration and training [28]. Moreover based on Albernaz's report face to face consultation increases exclusive breastfeeding rate because of continuous support, breastfeeding technical training and mothers' problem solving [29]. This finding shows more deliberate need for policy makers. Every day tens of public classes are held in private and public prenatal clinics and hospitals to improve breastfeeding knowledge, attitude and practice. This help received by women was not always useful. Moreover, in Baby Friendly Hospitals different methods like brochures, films, and health staff consultation are usually applied simultaneously to increase efficacy of training program, which should be revised. It is considered that mothers trust their doctors and one of the most effective factors on breastfeeding duration may be physicians' face to face training during different time periods.

Father's supports also were independently associated with breastfeeding continuity. A number of previous studies have confirmed our finding; Meedya et al. in 2010 and Sherriff et al. in 2014 demonstrated that beside mothers' intention and decision, social factors particularly fathers' supports in breastfeeding initiation and continuance are crucial [30] [31]. Breastfeeding seems a team work efforts which fathers' physical, practical, emotional, psychological attendance and supports are undeniable [32]. Kenosi found that children with short breastfeeding period had fathers with very restricted knowledge about breastfeeding and its advantages [33].

Immediately after birth, skin to skin contact was found as another efficient factor in this study. Based on UNICEF report (2006) infant and mother skin to skin contact in first hour of life is one of ten steps in breastfeeding success [34]. It has been reported that skin to skin contact is an effective intervention to promote babies' sucking ability, weight gain, body temperature stability and mother's satisfaction [35].

Our results on the influence of mother's birth trauma on breastfeeding duration are generally in line with those reported in other studies. It is considered that birth trauma causes some troubles and discomfort on mother's position. Brown et al. in their study confirmed that complications during labor and delivery may increase risk of specific physical difficulties with more breastfeeding failure. Both pain due to birth trauma and associated medications decrease breastfeeding duration [36] [37]. 
Despite the fact that our study highlights the status of breastfed infants born in Baby Friendly Hospitals (which are significant and well established in Iran), not evaluate all the related factors such as delivery status, economic factor and ethnicity in this study. Participants in our study were from urban areas and therefore are not representative of all Tehran population.

\section{Conclusion}

To determine the causes of short breastfeeding duration, this study was performed. Based on results, some reasons like insufficient breast milk supply, mothers' occupation, physician and family's recommendation, infant crying and restless, Mother's reluctance and infant refuse were the most common causes of stopping exclusively breastfeeding. On the other hand, training course particularly physician's face to face education and father's support can influence on exclusive breastfeeding and breastfeeding duration significantly. It seems lots of public health efforts and policy are needed to improve breastfeeding rate in our country.

\section{Acknowledgements}

The authors would like to thank Fetal, Maternal and Neonatal Research Center for financial support.

\section{Authors' Contribution}

Dr Nayeri and Dr Dalili were responsible for concepts, design, editing Manuscript and Experimental studies, Dr Shariat and Dr Raji did Literature search, Data acquisition, Data analysis, and Statistical analysis and Dr Karimi prepared and reviewed manuscript.

\section{References}

[1] Şencan, I., Tekin, O. and Mansur, T.M. (2013) Factors Influencing Breastfeeding Duration: A Survey in a Turkish Population. European Journal of Pediatrics, 172, 1459-1466. http://dx.doi.org/10.1007/s00431-013-2066-8

[2] Assarian, F., Moravveji, A., Ghaffarian, H., Eslamian, R. and Atoof, F. (2014) The Association of Postpartum Maternal Mental Health with Breastfeeding Status of Mothers: A Case-Control Study. Iranian Red Crescent Medical Journal, 16, e14839. http://dx.doi.org/10.5812/ircmj.14839

[3] http://www.who.int/maternal child adolescent/news events/news/2012/30 $07 \quad 2012$

[4] Froehlich, J., Boivin, M., Walter, K.C., Bloch, M.K., Rice, D., McGraw, K. and Munson, E. (2013) Influencing University Students’ Knowledge and Attitudes toward Breast Feeding. Journal of Nutrition Education and Behavior, 1-3.

[5] Li, R., Zhao, Z., Mokdad, A., Barker, L. and Grummer-Strawn, L. (2003) Prevalence of Breastfeeding in the United States: The 2001 National Immunization Survey. Pediatrics, 111, 1198-1201.

[6] Perez-Escarnilla, R., Lutter, C., Segall, A.M., et al. (1995) Exclusive Breast-Feeding Duration Is Associated with Attitudinal, Socioeconomic and Biocultural Determinants in Three Latin American Countries. Nutrition Journal, 12, 2972.

[7] Rosenberg, K.D., Eastham, C.A. and Kasehagen, L.J. (2008) Marketing Infant Formula through Hospitals: The Impact of Commercial Hospital Discharge Packs on Breast Feeding. American Journal of Public Health, 98, 290-295. http://dx.doi.org/10.2105/AJPH.2006.103218

[8] http://www.aafp.org/online/en/home

[9] Dalili, H., Farsar, A., Barakati, H., Raij, F., Shariat, M., Pourmalek, F., et al. (2014) Frequency of Exclusive Breastfeeding and Its Affecting Factors in Tehran, 2011. Acta Medica Iranica, 52, 552-556.

[10] The Ministry of Health IR of Iran, Breastfeeding Office. http://www.bfps.ir/(i5emlr45w1kdeg45tov0ysem)/Persian/Home.aspx

[11] Marandi, A., Afzali, H.M. and Hossaini, A.F. (1993) The Reasons for Early Weaning among Mothers in Teheran. Bulletin of the World Health Organization, 71, 561-569.

[12] Veghari, G.H., Mansourian, A. and Abdollahi, A. (2011) Breastfeeding Status and Some Related Factors in Northern Iran. Oman Medical Journal, 26, 342-348. http://dx.doi.org/10.5001/omj.2011.84

[13] World Health Organization (1991) Indicators for Assessing Breast-Feeding Practices. World Health Organization, Geneva.

[14] Wenru, W., Ying, L., Aloysius, C. and Kin, S.C. (2014) Breast-Feeding Intention, Initiation and Duration among Hong Kong Chinese Women: A Prospective Longitudinal Study. Midwifery, 30, 678-687. 
http://dx.doi.org/10.1016/j.midw.2013.07.015

[15] Al Juaid, D.A., Binns, C.W. and Giglia, R.C. (2014) Breastfeeding in Saudi Arabia: A Review. International Breastfeeding Journal, 9, 1-9. http://dx.doi.org/10.1186/1746-4358-9-1

[16] Liu, P., Qiao, L., Xu, F., Zhang, M., Wang, Y. and Binns, C.W. (2013) Factors Associated with Breastfeeding Duration: A 30-Month Cohort Study in Northwest China. Journal of Human Lactation, 29, 253-259. http://dx.doi.org/10.1177/0890334413477240

[17] Spear, H.J. (2004) Nurses’ Attitudes, Knowledge, and Beliefs Related to the Promotion of Breastfeeding among Women Who Bear Children during Adolescence. Journal of Pediatric Nursing, 19, 176-183. http://dx.doi.org/10.1016/j.pedn.2004.01.006

[18] Garbarino, F., Morniroli, D., Ghirardi, B., Garavaglia, E., Bracco, B., Gianní, M.L., Roggero, P. and Mosca, F. (2013) Prevalence and Duration of Breastfeeding during the First Six Months of Life: Factors Affecting an Early Cessation. La Pediatria Medica e Chirurgica, 35, 217-222. http://dx.doi.org/10.4081/pmc.2013.30

[19] Tarrant, M., Fong, D.Y., Wu, K.M., Lee, I.L., Wong, M.E., et al. (2010) Breast Feeding \& Weaning Practices among Hong Kong Mothers, a Prospective Study. BMC Pregnancy \& Childbirth, 10, 1-12.

[20] Li, R., Fein, S.B., Chen, J. and Grummer, S. (2008) Why Mothers Stop Breast Feeding: Self Reported Reason for Stopping during First Year. Pediatrics, 122, S69-S76. http://dx.doi.org/10.1542/peds.2008-1315i

[21] Amir, L.H. and Cwikel, J. (2005) Why Do Women Stop Breastfeeding? A Closer Look at “Not Enough Milk” among Israeli Women in the Negev Region. Breastfeed Re, 13, 7-13.

[22] Amir, L.H. (2006) Breastfeeding, Managing Supply Difficulties. Australian Family Physicians, 35, 686-689.

[23] Ong, G., Yap, M., Li, F.L. and Choo, T.B. (2005) Impact of Working Status Ion Breastfeeding in Singapore. European Journal of Public Health, 15, 424-430. http://dx.doi.org/10.1093/eurpub/cki030

[24] Nagulesapillai, T., McDonald, S.W., Fenton, T.R., Mercader, H.F. and Tough, S. (2013) Breastfeeding Difficulties and Exclusivity among Late Preterm and Term Infants: Results from the All Our Babies Study. Canadian Journal of Public Health, 104, 351-356.

[25] Haschke, F., Haiden, N., Detzel. P., Yarnoff, B., Allaire, B. and Haschke-Becher, E. (2013) Feeding Patterns during the First 2 Years and Health Outcome. Annals of Nutrition and Metabolism, 62, 16-25. http://dx.doi.org/10.1159/000351575

[26] Niela-Vilén, H., Axelin, A., Melender, H.L. and Salanterä, S. (2014) Aiming to Be a Breastfeeding Mother in a Neonatal Intensive Care Unit and at Home: A Thematic Analysis of Peer-Support Group Discussion in Social Media. Maternal \& Child Nutrition. http://dx.doi.org/10.1111/mcn.12108

[27] Haroon, S., Das, J.K., Salam, R.A., Imdad, A. and Bhutta, Z.A. (2013) Breastfeeding Promotion Interventions and Breastfeeding Practices: A Systematic Review. BMC Public Health, 13, 20. http://dx.doi.org/10.1186/1471-2458-13-S3-S20

[28] Handa, D. and Schanler, R.J. (2013) Role of the Pediatrician in Breastfeeding Management. Pediatric Clinics of North America, 60, 1-10. http://dx.doi.org/10.1016/j.pcl.2012.10.004

[29] Albernaz, E. and Victora C.G. (2003) Impact of Face-to-Face Counseling on Duration of Exclusive Breast-Feeding: A Review. Revista Panamericana de Salud Pública, 14, 17-24. http://dx.doi.org/10.1590/S1020-49892003000600004

[30] Meedya, S., Fahy, K. and Kable, A. (2010) Factors That Positively Influence Breastfeeding Duration to 6 Months: A Literature Review. Women and Birth, 23, 135-145. http://dx.doi.org/10.1016/j.wombi.2010.02.002

[31] Sherriff, N., Panton, C. and Hall, V. (2014) A New Model of Father Support to Promote Breastfeeding. The Journal of Community Practice, 87, 20-24.

[32] Tohotoa. J., Maycock, B., Hauck, Y.L., Howat, P., Burns, S. and Binns, C.W. (2009) Dads Make a Difference: An Exploratory Study of Paternal Support for Breastfeeding in Perth, Western Australia. International Breastfeeding Journal, 4, 15. http://dx.doi.org/10.1186/1746-4358-4-15

[33] Kenosi, M., Hawkes, C.P., Dempsey, E.M. and Ryan, C.A. (2011) Are Fathers Underused Advocates for Breastfeeding? Irish Medical Journal, 104, 313-315.

[34] Grizzard, T.A., Bartick, M., Nikolov, M., Griffin, B.A. and Lee, K.G. (2006) Policies and Practices Related to Breastfeeding in Massachusetts: Hospital Implementation of the Ten Steps to Successful Breastfeeding. Maternal and Child Health Journal, 10, 247-263.

[35] Srivastava, S., Gupta, A., Bhatnagar, A. and Dutta, S. (2014) Effect of Very Early Skin to Skin Contact on Success at Breastfeeding and Preventing Early Hypothermia in Neonates. Indian Journal Public Health, 58, 22-26. http://dx.doi.org/10.4103/0019-557X.128160 
[36] Brown, A. and Jordan, S. (2013) Impact of Birth Complications on Breastfeeding Duration: An Internet Survey. Journal of Advanced Nursing, 69, 828-839. http://dx.doi.org/10.1111/j.1365-2648.2012.06067.X

[37] Khabbal, Y., Zaoui, S. and Cherrah, Y. (2013) Medicines and Breastfeeding: Assessing the Risk of Medicines to Infants. Eastern Mediterranean Health Journal, 19, 186-191. 